\title{
Composição química e perfil de ácidos graxos da carne de bovinos de diferentes condições sexuais recebendo silagem de milho e concentrado ou cana-de-açúcar e concentrado contendo grãos de girassol ${ }^{1}$
}

\section{Alexandre Rodrigo Mendes Fernandes ${ }^{2}$, Alexandre Amstalden Moraes Sampaio ${ }^{3}$, Wignez Henrique $^{4}$, Rymer Ramiz Tullio ${ }^{5}$, Emanuel Almeida de Oliveira ${ }^{6}$, Tiago Máximo da Silva ${ }^{6}$}

\author{
${ }^{1}$ Agência financiadora: $C N P q$. \\ 2 Pós-Doutorando - Departamento de Zootecnia - FCAV/UNESP. Bolsista Fapesp. \\ ${ }^{3}$ Departamento de Zootecnia - FCAV/Unesp, Bolsista CNPq \\ ${ }^{4}$ APTA - São José do Rio Preto, SP. \\ 5 Embrapa CPPSE - São Carlos, SP. \\ 6 Programa de Pós-Graduação em Zootecnia-FCAV/Unesp.
}

RESUMO - O objetivo neste trabalho foi avaliar as características químicas e a composição em ácidos graxos do contrafilé (músculo Longissimus) de tourinhos, novilhos e novilhas da raça Canchim. Os animais foram terminados em confinamento com duas dietas experimentais, uma com silagem de milho e concentrado e outra com cana-de-açúcar e concentrado contendo grãos de girassol. Os teores de umidade, proteína e minerais no músculo não diferiram entre as dietas e as condições sexuais dos animais. A carne de novilhos terminados com a dieta com grãos de girassol apresentou maior teor de lipídios (3,31\%) em comparação à dos animais de outras categorias. Os animais que receberam a dieta com grãos de girassol apresentaram maiores concentrações de ácido linoléico conjugado (18:2 cis9, trans-11) $(0,73 \%)$ e ácidos graxos poliinsaturados $(8,12 \%)$ no músculo, e também relações mais elevadas de ácidos graxos insaturados:saturados $(0,93)$ e ácidos graxos poliinsaturados:saturados $(0,16)$ em comparação àqueles que receberam a dieta convencional, à base de silagem de milho $(0,34 \%$; $6,31 \%$; 0,86 ; e 0,11 , respectivamente). A composição em ácidos graxos da carne de bovinos pode ser melhorada com a utilização de cana-de-açúcar e grãos de girassol na dieta dos animais terminados em confinamento.

Palavras-chave: ácidos graxos insaturados, ácidos graxos saturados, ácido linoléico conjugado

\section{Chemical traits and fatty acids composition of beef from young bulls, steers and heifers fed corn silage and concentrate or sugarcane and concentrate with sunflower grains}

\begin{abstract}
The objective in this work was to evaluate the chemical characteristics and the fatty acids composition of beef loin (Longissimus muscle) of young bulls, steers and heifers of Canchim breed. The animals were finished in feedlot system and fed two experimental diets, one with corn silage and concentrate (SIL) and the other with sugar cane, as exclusive roughage, and concentrate containing sunflower grains (CNA). Differences were not detected in relation to moisture, protein and mineral contents between diets or sexual categories. The meat from steers that received the CNA diet had higher lipid content (3.31\%) in relation to meat from young bulls and heifers receiving the same diet. The meat from animals that received the CNA diet had higher concentrations of conjugated linoleic acid (18:2 cis-9, trans-11) and polyunsaturated fatty acids, and showed higher unsaturated fatty acids:saturated fatty acids and polyunsaturated fatty acids:saturated fatty acids ratios than those of animals fed with SIL diet; respectively 0.73 and $0.34 \%$; 8.12 and $6.31 \% ; 0.93$ and $0.86 ; 0.16$ and 0.11 . The fatty acids composition in meat from beef cattle can be improved with the utilization of sugar cane and sunflower grains in the finishing diet.
\end{abstract}

Key Words: conjugated linoleic acid, saturated fatty acids, unsaturated fatty acids

\section{Introdução}

Atualmente, a pesquisa tem evoluído em investigações para melhorar a qualidade da carne bovina, conquistar o consumidor e ampliar a competição com as carnes de aves e suínos. A qualidade da carne bovina normalmente é avaliada por características sensoriais, como cor, textura, maciez e palatabilidade. No entanto, outros aspectos também

Este artigo foi recebido em 26/6/2007 e aprovado em 28/8/2008.

Correspondências devem ser enviadas para: sampaio@fcav.unesp.br 
são relevantes na avaliação da qualidade, entre eles, o teor de gordura e sua composição em ácidos graxos, principalmente, poliinsaturados e ácido linoléico conjugado (CLA).

A gordura da carne dos ruminantes apresenta maior concentração de ácidos graxos saturados e menor relação poliinsaturados:saturados em comparação à da carne de não-ruminantes, principalmente em virtude do processo de biohidrogenação dos ácidos graxos não-saturados no rúmen pela ação dos microrganismos (French et al., 2000).

Wood et al. (2003) relataram que o crescente interesse no desenvolvimento de estratégias de manipulação da composição de ácidos graxos da carne bovina está relacionado à necessidade de se produzir carne mais saudável para reduzir a associação do consumo de carne bovina à ocorrência dessas doenças. French et al. (2000) observaram que o aumento na proporção de forragem na dieta de bovinos proporcionou decréscimo linear na concentração intramuscular de ácidos graxos saturados e aumento na relação poliinsaturados:saturados e na concentração de ácido linoléico conjugado. Mir et al. (2003), no entanto, observaram que grãos ricos em ácidos graxos poliinsaturados, como o girassol (Helianthus annuus), podem ser uma alternativa na alimentação de bovinos para aumento da síntese de CLA no rúmen, como produto intermediário da hidrogenação do ácido linoléico, encontrado em grande concentração nesse alimento.

De acordo com Zembayashi et al. (1995), a raça e o sexo dos animais têm grande influência na composição em ácidos graxos dos lipídios da carne, pois determinam diferenças na deposição de gordura corporal.

Diante dessas observações, objetivou-se avaliar as características químicas e a composição em ácidos graxos da carne de bovinos Canchim de diferentes condições sexuais terminados em confinamento com uma dieta contendo grãos de girassol.

\section{Material e Métodos}

O trabalho foi desenvolvido no Setor de Bovinocultura de Corte da FCAV/Unesp. Foram utilizados 30 animais da raça Canchim com aproximadamente 15 meses de idade: 10 tourinhos $(295 \pm 14 \mathrm{~kg}), 10$ novilhos $(290 \pm 18 \mathrm{~kg})$ castrados 30 dias antes do início da adaptação e 10 novilhas ( $280 \pm 21 \mathrm{~kg}$ de peso corporal). Todos os animais receberam tratamentos sanitários antes do início do experimento e foram adaptados às instalações e ao manejo experimental durante 21 dias. Os animais foram mantidos em confinamento durante 105 dias, alojados em baias individuais de $16 \mathrm{~m}^{2}$, providas de cochos cobertos para alimentação e bebedouros. O manejo experimental e o desempenho dos animais no confinamento foram descritos por Fernandes et al. (2007). Todos os procedimentos experimentais foram submetidos à apreciação e aprovados pela Comissão de Ética e Bem-Estar Animal (CEBEA).

As dietas (Tabela 1) foram formuladas de acordo com o sistema CNCPS, desenvolvido por Fox et al. (1992), para propiciarem ganhos de $1,3 \mathrm{~kg} / \mathrm{dia}$. O girassol em grão apresentou $89,2 \%$ de matéria seca, com $29,6 \%$ de proteína bruta, $38,0 \%$ de extrato etéreo e $20,3 \%$ de fibra em detergente neutro.

A variedade de cana-de-açúcar utilizada foi a forrageira IAC 86-2480, que apresenta boa produtividade, alto teor de açúcar e baixo teor de fibra, com grande potencial para alimentação animal, conforme descrito por Landell et al. (2002). O corte da cana-de-açúcar foi realizado manualmente, em dias alternados, com a picagem (partículas de aproximadamente $2 \mathrm{~cm}$ ) em picadeira estacionária imediatamente antes do fornecimento aos animais. Os ingredientes utilizados na composição dos concentrados foram triturados em moinho provido de peneira com crivos de $2 \mathrm{~mm}$ e posteriormente, a mistura foi preparada em misturador horizontal por 5 minutos.

$\mathrm{O}$ alimento foi fornecido à vontade, na forma de ração completa, em duas refeições: $40 \%$ da quantidade diária na primeira $(8 \mathrm{~h})$ e $60 \%$ na segunda refeição $(14 \mathrm{~h})$. Durante

Tabela 1 - Composição dos volumosos e das dietas experimentais

\begin{tabular}{|c|c|c|c|}
\hline \multirow[t]{2}{*}{ Volumoso } & \multicolumn{3}{|c|}{ Composição bromatológica } \\
\hline & MS (\%) & $\mathrm{PB}(\% \mathrm{MS})$ & FDN (\% MS) \\
\hline Cana-de-açúcar & 24,29 & 3,59 & 37,91 \\
\hline Silagem de milho & 29,76 & 7,86 & 48,24 \\
\hline \multirow[t]{2}{*}{ Ingrediente } & \multicolumn{3}{|c|}{$\operatorname{Dieta}^{1}(\%$ MS $)$} \\
\hline & \multicolumn{2}{|l|}{ Convencional } & Grãos de girassol \\
\hline Cana-de-açúcar & \multicolumn{2}{|l|}{ 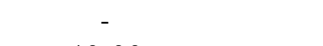 } & 40,00 \\
\hline Silagem de milho & \multicolumn{2}{|l|}{40,00} & - \\
\hline Grãos de girassol & \multirow{2}{*}{\multicolumn{2}{|c|}{10,60}} & 11,30 \\
\hline Farelo de soja & & & 13,65 \\
\hline Milho em grão moído & \multicolumn{2}{|l|}{35,50} & 22,15 \\
\hline Polpa cítrica & \multicolumn{2}{|l|}{11,00} & 10,00 \\
\hline Núcleo mineral & \multirow{2}{*}{\multicolumn{2}{|c|}{$\begin{array}{l}1,00 \\
0,40\end{array}$}} & 1,00 \\
\hline Uréia & & & 0,40 \\
\hline \multirow[t]{2}{*}{ Bicarbonato de sódio } & \multicolumn{2}{|l|}{1,50} & 1,50 \\
\hline & \multicolumn{3}{|c|}{ Perfil nutricional } \\
\hline \multicolumn{2}{|l|}{$\begin{array}{l}\text { Matéria seca }(\%) \\
\text { Proteína bruta (\% MS) }\end{array}$} & 51,00 & 48,00 \\
\hline Proteína bruta (\% MS) & & 14,00 & 14,05 \\
\hline \multirow{2}{*}{\multicolumn{2}{|c|}{$\begin{array}{l}\text { Nutrientes digestíveis totais (\% MS) } \\
\text { Energia metabolizável (MJ/kg MS) }\end{array}$}} & 75,00 & 74,00 \\
\hline \multirow{2}{*}{\multicolumn{2}{|c|}{$\begin{array}{l}\text { Energia metabolizável (MJ/kg MS) } \\
\text { Extrato etéreo (\% MS) }\end{array}$}} & 11,68 & 11,52 \\
\hline & & 3,10 & 4,10 \\
\hline
\end{tabular}


todo o período experimental, as quantidades fornecidas foram ajustadas para permitir em torno de $10 \%$ de sobras em relação ao total consumido no dia anterior.

Quando cada grupo (tourinhos, novilhos ou novilhas) atingiu o ponto adequado de acabamento (16@para os machose15@para as fêmeas, com cobertura de gordura mínima de $3 \mathrm{~mm}$, avaliada por ultra-som), os animais foram enviados para frigorífico comercial e abatidos conforme procedimento normal do estabelecimento. Os pesos de abate de tourinhos, machos castrados e fêmeas, foram: 468,8; $427,2 \mathrm{e} 416,8 \mathrm{~kg}$ as espessuras de gordura, 4,3; 5,6 e 5,3 mm, respectivamente (Fernandes et al., 2007).

As meias-carcaças foram mantidas em câmara frigorífica a $4^{\circ} \mathrm{C}$ por aproximadamente 24 horas. Após o resfriamento, uma seção do músculo Longissimus entre a $11^{\underline{a}}$ e $13^{\underline{a}}$ costelas de cada meia-carcaça esquerda foi retirada e encaminhada ao Laboratório de Tecnologia dos Produtos de Origem Animal da FCAV/Unesp. Duas fatias do músculo de cada animal, com aproximadamente $2,5 \mathrm{~cm}$ de espessura, foram retiradas para determinação do $\mathrm{pH}$. Ambos os bifes foram devidamente acondicionados em placas de Petri e secos em liofilizador por 48 horas. Os bifes foram moídos em processador de alimentos, com gelo seco, para evitar aquecimento e possíveis alterações químicas. No primeiro bife, foram determinados os teores de extrato etéreo, por extração em aparelho Soxhlet por 20 horas; de proteína, em aparelho Kjedhal; e minerais, pela queima do material em mufla a $600^{\circ} \mathrm{C}$ por 16 horas (Alleoni et al., 1997). Os teores de matéria seca foram determinados em estufa a $105^{\circ} \mathrm{C}$, uma vez que houve reabsorção de água nas amostras submetidas a análises laboratoriais, e os resultados obtidos corrigidos para matéria seca total.

O segundo bife foi utilizado para determinação da composição em ácidos graxos do músculo. A matéria graxa foi extraída com mistura de clorofórmio-metanol, segundo Bligh \& Dyer (1959), com modificações apresentadas por Tullio (2004). Aproximadamente $3 \mathrm{~g}$ de amostra liofilizada foram transferidos para frascos erlenmeyer de $125 \mathrm{~mL}$, que foram adicionados de $10 \mathrm{~mL}$ de clorofórmio, $20 \mathrm{~mL}$ de metanol e $8 \mathrm{~mL}$ de água destilada. Os frascos foram agitados por 30 minutos em mesa agitadora e, posteriormente, foram adicionados de $10 \mathrm{~mL}$ de clorofórmio e $10 \mathrm{~mL}$ de sulfato de sódio a $1,5 \%$, quando foram agitados novamente por 2 minutos em mesa agitadora. O material foi filtrado em papel-filtro quantitativo e transferido para tubos falcon de $50 \mathrm{~mL}$. Após a separação das camadas, a superior, metanóica, foi descartada. Do filtrado restante, $10 \mathrm{~mL}$ foram transferidos para frascos béquer de $50 \mathrm{~mL}$, previamente tarados, que foram levados para estufa de circulação de ar forçada, a $55^{\circ} \mathrm{C}$, para evaporação do solvente, por 24 horas, e depois acondicionados em dessecador para atingirem a temperatura ambiente e posterior pesagem. Pela diferença do peso do béquer, foram calculados os teores de lipídios das amostras.

Para transesterificação dos triglicerídeos, parte da matéria lipídica extraída (aproximadamente $50 \mathrm{mg}$ ) foi transferida para tubos falcon de $15 \mathrm{~mL}$, nos quais foram adicionados $2 \mathrm{~mL}$ de $\mathrm{n}$-heptano. A mistura foi agitada até a completa dissolução da matéria graxa e adicionada de $2 \mathrm{~mL}$ de KOH 2 mol/L em metanol. A mistura foi agitada por aproximadamente 5 minutos e, após a separação das fases, $1 \mathrm{~mL}$ da fase superior (heptano e ésteres metílicos de ácidos graxos) foi transferido para frascos eppendorf de $1,5 \mathrm{~mL}$, que foram hermeticamente fechados, protegidos da luz e armazenados em congelador a $-18^{\circ} \mathrm{C}$, para posterior análise cromatográfica.

As análises da composição de ácidos graxos foram realizadas no Laboratório de Bioquímica do Departamento de Agroindústria, Alimentos e Nutrição da Escola Superior de Agricultura Luiz de Queiroz/USP. O perfil de ácidos graxos foi determinado por cromatografia gasosa de alta resolução utilizando-se cromatógrafo a gás equipado com coluna capilar SP-2560 de $100 \mathrm{~m}$ de comprimento e diâmetro de $0,25 \mathrm{~mm}$ acoplado a um detector de ionização de chama. A temperatura foi programada para iniciar em $130^{\circ} \mathrm{C}$ e manter-se assim por 1 minuto, quando foi elevada a $170^{\circ} \mathrm{C}$ a taxa de $6,5^{\circ} \mathrm{C} /$ minuto. Posteriormente, outra elevação de temperatura de 170 a $215^{\circ} \mathrm{C}$, foi realizada a $2,75^{\circ} \mathrm{C} /$ minuto e mantida por 12 minutos. Finalmente, uma última elevação foi realizada de 215 para $230^{\circ} \mathrm{C}$ a uma taxa de $40^{\circ} \mathrm{C} /$ minuto. As temperaturas do injetor e detector foram de 270 e $280^{\circ} \mathrm{C}$, respectivamente, e as amostras de $0,3 \mu \mathrm{L}$ foram injetadas em modo "split", utilizando-se hidrogênio como gás carreador. A identificação dos ésteres metílicos de ácidos graxos foi realizada por comparação com os tempos de retenção e as concentrações dos ácidos graxos de padrões autênticos, metilados e eluídos nas mesmas condições.

Todos os resultados obtidos foram submetidos a análise de variância, utilizando-se o procedimento GLM (SAS, 2001), em que o modelo estatístico incluiu os efeitos de condição sexual (tourinho, novilho e novilha) e tipo de alimentação (dieta controle e dieta teste) e suas interações. Quando as interações foram significativas, os fatores foram considerados dependentes e as médias comparadas apenas entre si. As médias foram comparadas pelo teste Tukey, com nível de significância de 5\% de probabilidade quando o teste $\mathrm{F}$ foi significativo para a variável ou a interação. 


\section{Resultados e Discussão}

Não foi observada interação ou efeito significativo $(\mathrm{P}>0,05)$ da condição sexual e das dietas sobre os teores de umidade, proteína e minerais do músculo e sobre o $\mathrm{pH}$ da carne (Tabela 2).

Os animais foram abatidos aos 18 meses de idade e o Longissimus apresentou teores de umidade superiores aos observados por Vaz et al. (2001), que encontraram $71,36 \%$ de umidade na carne de animais castrados ou nãocastrados de diferentes grupos genéticos Charolês $\times$ Nelore terminados em confinamento e abatidos aos 24 meses de idade. Esses resultados são coerentes com a afirmativa de Lawrie (2005) de que animais jovens apresentam maior proporção de água no músculo. Além disso, o teor de gordura corporal nos animais mais velhos é maior, o que também contribui para a diminuição no teor de água corporal.

Não foram verificadas diferenças $(\mathrm{P}>0,05)$ no $\mathrm{pH}$ da carne entre as condições sexuais e dietas (Tabela 3). Os valores encontrados foram inferiores a 5,8, que, conforme descrito por Gregory (1998), seria o valor limite para a ocorrência de carnes tipo DFD (dark, firm and dry). Segundo esse autor, tourinhos podem ser mais susceptíveis ao estresse, o que pode contribuir para que a redução do $\mathrm{pH}$ durante o resfriamento não seja efetiva, fenômeno que não foi observado neste trabalho.

A análise estatística do teor de extrato etéreo no músculo Longissimus comprovou interação significativa $(\mathrm{P}<0,05)$ entre os fatores condição sexual e dietas (Tabela 3). A dieta com silagem de milho como volumoso não alterou $(\mathrm{P}>0,05)$ o conteúdo de extrato etéreo do músculo dos animais de nenhuma das condições sexuais avaliadas (Tabela 3 ). Por outro lado, o teor de extrato etéreo muscular nos novilhos mantidos com a dieta com cana-de-açúcar e girassol foi maior que o dos tourinhos $(\mathrm{P}<0,05)$, enquanto o das novilhas foi intermediário.

Em comparação aos tourinhos, novilhos e novilhas apresentam maior potencial para deposição de gordura, ocasionado pela diferença na curva de crescimento entre essas categorias animais. As fêmeas são mais precoces e geralmente têm menor tamanho corporal, enquanto os machos não-castrados são maiores e mais tardios e os machos castrados têm desenvolvimento intermediário (Luchiari Fiho, 2000). Quando animais dessas categorias são mantidos com dietas com mesmo teor de energia, a deposição de gordura nos machos não-castrados é atrasada, em virtude do desenvolvimento muscular mais prolongado, decorrente não só dos

Tabela 2 - Teores de umidade, proteína e minerais e pH do músculo Longissimus de bovinos Canchim terminados em confinamento com dieta convencional ou à base de cana-de-açúcar e concentrado contendo grãos de girassol

\begin{tabular}{|c|c|c|c|c|c|c|c|c|}
\hline & \multicolumn{3}{|c|}{ Condição sexual } & \multirow[b]{2}{*}{$\mathrm{P}^{2}$} & \multicolumn{2}{|c|}{ Dieta $^{1}$} & \multirow[b]{2}{*}{$\mathrm{P}^{2}$} & \multirow[b]{2}{*}{$\mathrm{CV}^{3}(\%)$} \\
\hline & Tourinhos & Novilhos & Novilhas & & Convencional & Grãos de girassol & & \\
\hline Umidade & 75,08 & 73,86 & 74,50 & 0,28 & 74,71 & 74,26 & 0,06 & 1,66 \\
\hline Proteína & 21,49 & 21,44 & 21,36 & 0,19 & 21,12 & 21,74 & 0,97 & 5,86 \\
\hline Minerais & 0,98 & 1,01 & 1,01 & 0,40 & 0,99 & 1,01 & 0,20 & 5,06 \\
\hline $\mathrm{pH}$ & 5,69 & 5,65 & 5,70 & 0,37 & 5,63 & 5,73 & 0,09 & 2,68 \\
\hline
\end{tabular}

${ }^{1}$ Convencional - Dieta convencional à base de silagem de milho e concentrado; Grãos de girassol - Dieta à base de cana-de-açúcar e concentrado contendo grãos de girassol.

${ }^{2} \mathrm{P}$ - probabilidade; ${ }^{3} \mathrm{CV}$ - coeficiente de variação.

Tabela 3 - Porcentagem de extrato etéreo do músculo Longissimus de bovinos Canchim terminados em confinamento com dieta convencional ou à base de cana-de-açúcar e concentrado contendo grãos de girassol

\begin{tabular}{lccc}
\hline Condição sexual & \multicolumn{2}{c}{ Dieta $^{1}$} & Média \\
\cline { 2 - 3 } & Convencional & Grãos de girassol & \\
\hline Tourinhos & $2,24 \mathrm{Ab}$ & $2,86 \mathrm{Ba}$ & 2,55 \\
Novilhos & $2,65 \mathrm{Ab}$ & $3,31 \mathrm{Aa}$ & 2,98 \\
Novilhas & $2,35 \mathrm{Ab}$ & $3,02 \mathrm{ABa}$ & 2,68 \\
Média & 2,62 & 2,86 & \\
\hline
\end{tabular}

Médias seguidas por letras diferentes, na mesma coluna (maiúsculas) ou na mesma linha (minúsculas), diferem pelo teste Tukey a $5 \%$ de probabilidade.

${ }^{1}$ Convencional - Dieta convencional à base de silagem de milho e concentrado Grão de girassol - Dieta à base de cana-de-açúcar e concentrado contendo grãos de girassol.

$\mathrm{P}=0,03 ; \mathrm{CV}=21,64 \%$ efeitos do nível mais elevado da testosterona, mas também de outros hormônios, que, segundo Lawrence \& Fowler (2002), também têm efeito acentuado em outros tecidos.

Conforme relatado por Zembayashi et al. (1995) em pesquisa com novilhos e novilhas de diversos cruzamentos entre as raças Wagyu e Holandesa, as maiores diferenças no teor de extrato etéreo muscular são decorrentes da condição sexual, enquanto a composição genética, nesse caso, tem menor efeito. Nurnberg et al. (2005) avaliaram tourinhos das raças Simental e Holandesa mantidos em confinamento e observaram, respectivamente, médias de 2,67 e 2,61\% de extrato etéreo muscular. $\mathrm{O}$ teor de extrato etéreo muscular 
está associado às variações na característica de maciez da carne e, por contribuir com o sabor, o aroma e a textura da carne, é importante para classificação das carcaças (Koohmaraie et al., 1996).

Neste estudo, em todas as condições sexuais, o teor de extrato etéreo obtido com a dieta com silagem de milho foi menor $(\mathrm{P}<0,05)$ que aquele obtido com a dieta com cana-deaçúcar e grãos de girassol (Tabela 3), o que comprova a possibilidade de alteração da qualidade da carne pela manipulação da dieta dos animais (Wood t al., 2003). Uma vez que as dietas eram isoenergéticas, é possível que a dieta com cana-de-açúcar, em razão de seu maior teor de sacarose, tenha propiciado a produção de ácido propiônico no rúmen e disponibilizado mais glicose para o animal, elevando o teor de extrato etéreo da carne.

Não foi observado efeito significativo $(\mathrm{P}>0,05)$ da interação condição sexual $\times$ dietas sobre a composição em ácidos graxos do músculo Longissimus (Tabela 4). A carne dos tourinhos apresentou maior $(\mathrm{P}<0,05)$ teor do ácido pentadecanóico (C15:0) em comparação à dos novilhos e das novilhas (Tabela 4). Os ácidos graxos de cadeia ímpar pouco comuns nos lipídeos da maioria dos mamíferos, porém, em ruminantes, são formados pela síntese de novo a partir do ácido propiônico, produzido no processo de fermentação ruminal.
Zembayashi et al. (1995) não observaram diferenças no teor de C15:0 no músculo Longissimus dorsi de novilhos e novilhas $(0,13 \%)$. Neste estudo, no entanto, as novilhas apresentaram maior $(\mathrm{P}<0,05)$ teor de ácido oléico $(\mathrm{C} 18: 1 \mathrm{c} 9)$ em comparação aos tourinhos e não diferiram dos novilhos, que apresentaram valor intermediário. $\mathrm{O}$ aumento na concentração do ácido oléico é altamente desejável, pois, conforme relatado por Mir et al. (2003), este ácido graxo é reconhecido por apresentar propriedades hipocolesterolêmicas. Kazala et al. (1999) avaliaram a composição de ácidos graxos do músculo de animais de diversos cruzamentos da raça Wagyu e constataram grande potencial para deposição de gordura intramuscular em comparação a bovinos de corte de outras raças. Esses autores observaram no músculo Longissimus teor médio de C18:1 c9, de 42,58\%. As novilhas utilizadas neste trabalho também apresentaram maior concentração deste ácido graxo em comparação aos novilhos, o que pode estar relacionado à maior atividade da enzima $\Delta^{9}$-dessaturase (18) nas fêmeas, que, de acordo com Kazala et al. (1999), atuam na conversão dos ácidos mirístico, palmítico e esteárico em seus correspondentes ácidos monoinsaturados (n-9).

Neste estudo o teor de C18:1 c9 observado nas fêmeas (Tabela 4) foi próximo ao relatado por Enser et al. (1998), que realizaram um levantamento para avaliar a composição de

Tabela 4 - Composição percentual em ácidos graxos do músculo Longissimus de bovinos Canchim com dieta convencional ou à base de cana-de-açúcar e concentrado contendo grãos de girassol

\begin{tabular}{|c|c|c|c|c|c|c|c|c|}
\hline \multirow[t]{2}{*}{ Ácido $\operatorname{graxo}^{2}$} & \multicolumn{3}{|c|}{ Condição sexual } & \multirow[b]{2}{*}{$\mathrm{P}^{3}$} & \multicolumn{2}{|c|}{ Dieta $^{1}$} & \multirow[b]{2}{*}{$\mathrm{P}^{3}$} & \multirow[b]{2}{*}{$\mathrm{CV}^{4}(\%)$} \\
\hline & Tourinhos & Novilhos & Novilhas & & Convencional & Grãos de girassol & & \\
\hline $\begin{array}{l}\text { 14:0 } \\
\text { Mirístico }\end{array}$ & 4,98 & 4,54 & 3,75 & 0,11 & 4,42 & 4,43 & 0,99 & 29,06 \\
\hline $\begin{array}{l}\text { 14:1 c9 } \\
\text { Miristoléico }\end{array}$ & 1,62 & 1,46 & 1,31 & 0,42 & 1,48 & 1,45 & 0,90 & 35,02 \\
\hline $\begin{array}{l}15: 0 \\
\text { Pentadecanóico }\end{array}$ & $0,46 \mathrm{a}$ & $0,34 \mathrm{~b}$ & $0,31 \mathrm{~b}$ & 0,04 & 0,38 & 0,37 & 0,91 & 24,98 \\
\hline $\begin{array}{l}\text { 16:0 } \\
\text { Palmítico }\end{array}$ & 32,43 & 31,36 & 29,62 & 0,16 & 31,98 & 30,29 & 0,16 & 10,30 \\
\hline $\begin{array}{l}\text { 16:1 c9 } \\
\text { Palmitoléico }\end{array}$ & 4,63 & 4,63 & 4,25 & 0,62 & 4,85 & 4,16 & 0,08 & 22,48 \\
\hline $\begin{array}{l}\text { 17:0 } \\
\text { Heptadecanóico }\end{array}$ & 0,97 & 0,85 & 0,86 & 0,21 & 0,92 & 0,86 & 0,26 & 18,77 \\
\hline $\begin{array}{l}\text { 18:0 } \\
\text { Esteárico }\end{array}$ & 15,38 & 16,15 & 16,29 & 0,62 & 15,76 & 16,13 & 0,65 & 14,02 \\
\hline $\begin{array}{l}\text { 18:1 c9 } \\
\text { Oléico }\end{array}$ & $31,32 b$ & $33,86 a b$ & $35,96 a$ & 0,04 & 33,40 & 34,03 & 0,68 & 12,26 \\
\hline $\begin{array}{l}18: 2 \text { c9 c12 } \\
\text { Linoléico }\end{array}$ & 7,47 & 6,11 & 6,45 & 0,32 & $5,97 \mathrm{~b}$ & $7,38 \mathrm{a}$ & 0,04 & 30,89 \\
\hline $\begin{array}{l}18: 2 \mathrm{c} 9, \mathrm{t} 11 \\
\text { CLA }\end{array}$ & 0,53 & 0,51 & 0,56 & 0,75 & $0,34 \mathrm{~b}$ & $0,73 \mathrm{a}$ & 0,01 & 26,11 \\
\hline $\begin{array}{l}\text { 14:0 + 16:0 } \\
\text { Mirístico + Palmítico }\end{array}$ & 37,42 & 35,90 & 33,37 & 0,13 & 36,41 & 34,72 & 0,30 & 26,721 \\
\hline
\end{tabular}

Médias seguidas de letras diferentes, na mesma linha, diferem entre si pelo teste Tukey a $5 \%$ de probabilidade.

${ }_{1}^{1}$ Convencional - Dieta convencional à base de silagem de milho e concentrado; Grãos de girassol - Dieta à base de cana-de-açúcar e concentrado contendo grãos de girassol

$2 \%$ do total de ácidos graxos.

${ }^{3} \mathrm{P}$ - Probabilidade; ${ }^{4} \mathrm{CV}$ - coeficiente de variação. 
ácidos graxos da carne bovina, ovina e suína adquirida em diversos supermercados e observaram que a carne bovina apresentava teor de C18:1 c9 mais elevado, aproximadamente $36 \%$, com médias de 32,5 e 32,8\% de C18:1 c9 para a carne de ovinos e suínos, respectivamente. As condições sexuais e as dietas estudadas não promoveram efeitos significativos $(\mathrm{P}>0,05)$ nos teores dos ácidos mirístico (C14:0) e palmítico (C16:0) (Tabela 4). Conforme relatado por Scollan et al. (2006), os ácidos graxos saturados predominantes na carne bovina são os C14:0, C16:0 e C18:0 (o C18:0 representa aproximadamente 30\% do total de ácidos graxos saturados). Os ácidos graxos saturados são correlacionados ao nível plasmático de colesterol e promovem elevação do nível de LDL (low density lipoprotein), embora o C16:0 seja menos prejudicial que o C14:0. De acordo com Scollan et al. (2006), o C18:0 é considerado neutro quanto ao nível de colesterol plasmático.

Não foi observado efeito $(\mathrm{P}>0,05)$ da condição sexual sobre o teor do ácido linoléico conjugado (cis9-trans11, CLA) do músculo Longissimus (Tabela 4). De La Torre et al. (2006) relataram que fatores intrínsecos aos animais, como raça, sexo e idade, podem influenciar o conteúdo de CLA nos produtos de animais ruminantes. Esses autores observaram que a taxa de deposição de CLA não depende da quantidade final de gordura corporal dos animais, mas é influenciada por outros fatores, como a idade do animal e principalmente a dieta.

A dieta com cana-de-açúcar e grãos de girassol proporcionou maiores teores $(\mathrm{P}<0,05)$ de ácido linoléico e CLA muscular dos animais em relação à dieta convencional, com silagem de milho. O aumento na concentração de CLA provavelmente esteve relacionado à inclusão de grãos de girassol, que tem grande concentração de ácido linoléico, e à utilização da cana-de-açúcar como volumoso. Essa combinação de ingredientes na dieta dos animais aumentou a síntese de CLA, como produto intermediário da hidrogenação do ácido linoléico, provavelmente promovido pelas bactérias ruminais, especialmente a espécie Butyrivibrio fibrisolvens, uma vez que o ambiente ruminal é propício para seu crescimento, principalmente com a inclusão da cana-de-açúcar (French et al., 2000; Mir et al., 2003). É possível ainda que esses ingredientes na dieta tenham promovido acúmulo de ácido vacênico (C18:1 t11) no rúmen, que foi absorvido e convertido a CLA no tecido adiposo, por ação da enzima dessaturase, embora a concentração desse ácido não tenha sido mensurada.

Dannenberger et al. (2004) descreveram dez isômeros de CLA em carne bovina e observaram que o isômero cis9-trans 11 representou $70 \%$ do total. Esses autores relataram que esse isômero possui reconhecidos efeitos anticarcinogênicos e antiteratogênicos e enfatizaram a grande importância da síntese endógena de CLA cis9trans 11, pela ação da enzima $\Delta^{9}$-dessaturase. Esse processo ocorreria a partir do ácido vacênico (C18:1 trans 11), produto intermediário formado durante o processo de biohidrogenação ruminal do ácido linoléico.

Não foram encontradas diferenças $(P>0,05)$ nos teores de ácidos graxos insaturados, monoinsaturados, poliinsaturados e nas relações insaturados:saturados, monoinsaturados:saturados e poliinsaturados:saturados, entre as diferentes condições sexuais (Tabela 5). Todavia, a dieta com cana-de-açúcar e grãos de girassol proporcionou $(\mathrm{P}<0,05)$ maior teor de ácidos graxos poliinsaturados e maiores relações insaturados:saturados e poliinsaturados:saturados.

De acordo com Enser et al. (1998), o Departamento de Saúde Britânico considera valor mínimo para uma dieta saudável a relação de 0,45 entre ácidos graxos poliinsaturados e ácidos graxos saturados. Os maiores valores para essa relação nesta pesquisa foram observados na carne dos animais terminados com a dieta contendo grãos de girassol e foram inferiores ao recomendado pela instituição. Os valores obtidos nas amostras provenientes

Tabela 5 - Perfil de ácidos graxos no músculo Longissimus de bovinos Canchim com dieta convencional ou à base de cana-de-açúcar e concentrado contendo grãos de girassol

\begin{tabular}{|c|c|c|c|c|c|c|c|c|}
\hline \multirow[t]{2}{*}{ Ácido graxo $^{2}$} & \multicolumn{3}{|c|}{ Condição sexual } & \multirow[b]{2}{*}{$\mathrm{P}^{3}$} & \multicolumn{2}{|c|}{ Dieta $^{1}$} & \multirow[b]{2}{*}{$\mathrm{P}^{3}$} & \multirow[b]{2}{*}{$\mathrm{CV}^{4}(\%)$} \\
\hline & Tourinhos & Novilhos & Novilhas & & Convencional & Grãos de girassol & & \\
\hline Saturados totais & 54,24 & 53,25 & 50,84 & 0,10 & 53,47 & 52,08 & 0,29 & 6,72 \\
\hline Monoinsaturados totais & 37,58 & 39,96 & 41,53 & 0,08 & 39,73 & 39,65 & 0,95 & 9,59 \\
\hline Poliinsaturados totais & 8,00 & 6,62 & 7,01 & 0,31 & $6,31 b$ & $8,12 \mathrm{a}$ & 0,02 & 28,30 \\
\hline Insaturados:saturados & 0,84 & 0,88 & 0,96 & 0,14 & $0,86 \mathrm{~b}$ & $0,93 \mathrm{a}$ & 0,04 & 14,16 \\
\hline Monoinsaturados:saturados & 0,69 & 0,75 & 0,82 & 0,08 & 0,74 & 0,77 & 0,57 & 15,77 \\
\hline Poliinsaturados:saturados & 0,15 & 0,12 & 0,14 & 0,44 & $0,11 \mathrm{~b}$ & $0,16 \mathrm{a}$ & 0,02 & 30,03 \\
\hline
\end{tabular}

Médias seguidas de letras diferentes, na mesma linha, diferem entre si pelo teste Tukey a $5 \%$ de probabilidade.

1 Convencional - Dieta convencional à base de silagem de milho e concentrado; Grãos de girassol - Dieta à base de cana-de-açúcar e concentrado contendo grãos de girassol

$2 \%$ do total de ácidos graxos.

${ }^{3} \mathrm{P}$ - Probabilidade; ${ }^{4} \mathrm{CV}$ - coeficiente de variação. 
dos animais mantidos com a dieta convencional, com silagem de milho, foram semelhantes ao valor médio de 0,11 observado por Enser et al. (1998) na carne de bovinos de corte na Inglaterra.

No trabalho de Malau-Aduli et al. (1998), em que foi avaliada a composição de ácidos graxos dos fosfolipídios musculares de novilhos e novilhas das raças Limousin e Jersey, a concentração de ácidos graxos monoinsaturados na carne dos novilhos foi maior que nas novilhas ( $42 \mathrm{e} 25 \%$, respectivamente), por outro lado, as novilhas apresentaram maior concentração de ácidos graxos poliinsaturados $(26,4 \mathrm{e}$ $11,6 \%)$ e maior relação poliinsaturados:saturados $(0,54 \mathrm{e}$ $0,27 \%$ ). Os resultados observados por esses autores podem indicar que as diferenças entre o perfil hormonal de novilhos e novilhas são influenciadas pelo metabolismo de lipídios não somente no tecido adiposo, mas também no sistema enzimático do tecido muscular. As diferenças, aparentemente, estão relacionadas ao sexo do animal e à raça estudada. Entretanto, conforme relatado por Malau-Aduli et al. (1998), esse mecanismo, especialmente em ruminantes, não está totalmente esclarecido.

No trabalho de French et al. (2000), a relação poliinsaturados:saturados aumentou de acordo com a participação de volumoso fresco na dieta dos animais, passando de 0,09 para 0,13. Esses autores afirmaram que essa ocorrência esteve associada à maior concentração de ácidos graxos $n-3$, principalmente o ácido linolênico, presente na forragem.

A maior concentração de ácidos graxos poliinsaturados no músculo dos animais mantidos com a dieta com grãos de girassol pode ser atribuída ao aumento da ingestão de C18:2 (ácido linoléico), proporcionado pelo maior aporte de ácidos graxos poliinsaturados do óleo contido nos grãos de girassol. Segundo Martin et al. (2006), os mamíferos não sintetizam o C18:2 e seus isômeros e, como os ácidos graxos desse grupo têm importantes funções na estrutura das membranas celulares e nos processos metabólicos, são considerados essenciais.

\section{Conclusões}

A terminação em confinamento de animais Canchim com dietas contendo grãos de girassol proporciona maior quantidade de ácido linoléico conjugado (cis9-trans11) e ácidos graxos poliinsaturados nos lipídios intramusculares e aumenta as relações ácidos graxos insaturados:saturados e poliinsaturados:saturados, o que torna a carne mais saudável. A composição em ácidos graxos da carne das novilhas é mais adequada para a alimentação humana que a de tourinhos e a de novilhos.

\section{Agradecimentos}

Ao Instituto Agronômico de Campinas (IAC), pela doação das mudas da variedade forrageira IAC 86-2480, para a formação do canavial experimental.

\section{Literatura Citada}

ALleONI, G.F.; LEME, P.R.; BOIN, C. et al. Avaliação da composição química e física dos cortes da costela para estimar a composição química corporal de novilhos Nelore. Revista Brasileira de Zootecnia, v.26, n.2, p.382-390, 1997.

BLIGH, E.G.; DYER, W.J. A rapid method of total lipid extraction and purification. Canadian Journal of Biochemistry and Physiology, v.37, p.911-917, 1959.

DANNENBERGER, D.; NUERNBERG, G.; SCOLLAN, N. et al. Effect of diet on the deposition of n-3 fatty acids, conjugated linoleic and C18:1 trans fatty acid isomers in muscle lipids of German Holstein bulls. Journal of Agriculture and Food Chemistry, v.52, n.21, p.6607-6615, 2004.

DE LA TORRE, A.; GRUFFAT, D.; DURAND, D. et al. Factors influencing proportion and composition of CLA in beef. Meat Science, v.73, n.2, p.258-268, 2006.

ENSER, M.; HALlLET, K.G.; HEWETT, B. et al. Fatty acid content and composition of UK beef and lamb muscle in relation to production system and implications for human nutrition. Meat Science, v.49, n.3, p.329-341, 1998.

FERNANDES, A.R.M.; SAMPAIO, A.A.M.; HENRIQUE, W. et al. Avaliação econômica e desempenho de machos e fêmeas em confinamento alimentados com dietas à base de silagem de milho e concentrado ou cana-de-açúcar e concentrado contendo grãos de girassol. Revista Brasileira de Zootecnia, v.36, n.4, p.855-864, 2007.

FRENCH P.; STANTON, C.; LAWLESS, F. et al. Fatty acid composition, including conjugated linoleic acid, of intramuscular fat from steers offered grazed grass, grass silage or concentrate based diets. Journal of Animal Science, v.78, n.11, p.2849$2855,2000$.

FOX, D.G.; SNIFFEN, C.J.; O'CONNOR, J.D. et al. A net carbohydrate and protein system for evaluating cattle diets: III Cattle requirements and diets adequacy. Journal of Animal Science, v.70, n.11, p.3578-3596, 1992.

GREGORY, N.G. Animal welfare and meat science. Cambridge: University Press, 1998. 289p.

LANDELL, M.G.A.; CAMPANA, M.P.; RODRIGUES, A.A. et al. A variedade IAC 86-2480 como nova opção de cana-deaçúcar para fins forrageiros: manejo de produção e uso na alimentação animal. Campinas: Instituto Agronômico, 2002. 39p. (Boletim Técnico, 193).

LAWRENCE, T.L.J.; FOWLER, V.R. Growth of farm animals. 2.ed. Wallingford: Cab Publishing, 2002. 347p.

LAWRIE, R.A. Ciência da carne. 6.ed. Porto Alegre: Artmed, 2005. 384 p.

LUCHIARI FILHO, A. A pecuária da carne bovina. São Paulo: A. Luchiari Filho, 2000. 134p.

KAZALA, E.C.; LOZEMAN, F.J.; MIR, P.S. et al. Relationship of fatty acid composition to intramuscular fat content in beef from crossbreed Wagyu cattle. Journal of Animal Science, v.77, n.7, p.1717-1725, 1999.

KOOHMARAIE, M.; WHEELER, T.L.; SHOCKELFORD, S.D. Sampling, cooking and coring effects on Warner-Bratzler shear force values in beef. Journal of Animal Science, v.74, n.7, p.1553-1562, 1996.

MALAU-ADULI, A.E.O.; SIEBERT, B.D.; BOTTEMA, C.D.K. et al. Breed comparison of muscle phospholipids in Jersey and limousine cattle. Journal of Animal Science, v.76, n.3, p.766-773, 1998. 
MARTIN, C.A.; ALMEIDA, V.V.; RUIZ, M.R. et al. Ácidos graxos poliinsaturados ômega-3 e ômega-6: importância e ocorrência em alimentos. Revista de Nutrição, v.19, n.6, p.761-770, 2006.

MIR, P.S.; IVAN, M.; HE, M.L. et al. Dietary manipulation to increase conjugated linoleic acids and other desirable fatty acids in beef: a review. Canadian Journal of Animal Science, v.83, n.4, p.673-685, 2003

NURNBERG, K.; DANNEMBERGER, D.; NUERNBERG, G. et al. Effect of a grass-based and a concentrate feeding system on meat quality characteristics and fatty acids composition of Longissimus lumborum muscle in different cattle breeds. Livestock Production Science, v.94, n.2, p.137-147, 2005.

STATISTICAL ANALYSIS SYSTEM - SAS. User's guide. Cary: SAS Institute, 2001. (CD-ROM).

SCOLLAN, N.; HOCQETTE, J.F.; NUERNBERG, K. et al. Innovations in beef production systems that enhance the nutritional and health value of beef lipids and their relationship with meat quality. Meat Science, v.74, n.1, p.17-33, 2006.

TULLIO, R.R. Estratégias de manejo para produção intensiva de bovinos visando à qualidade da carne. 2004. 107f. Tese (Doutorado em Zootecnia) - Faculdade de Ciências Agrárias e Veterinárias, Universidade Estadual Paulista, Jaboticabal, 2004.

VAZ, F.N.; RESTLE, J.; FEIJÓ, L.D.; et al. Qualidade da carne de bovinos de corte inteiros ou castrados de diferentes grupos genéticos Charolês x Nelore. Revista Brasileira de Zootecnia, v.30, n.2, p.518-525, 2001.

WOOD, J.D.; RICHARDSON, R.J.; NUTE, G.R. et al. Effects of fatty acids on meat quality: a review. Meat Science, v.66, n.1, p.21-32, 2003.

ZEMBAYASHI, M.; NISHIMURA, K.; LUNT, D.K. et al. Effects of breed type and sex on fatty acid composition of subcutaneous and intramuscular lipids of finishing steers and heifers. Journal of Animal Science, v.73, n.11, p.3325-3332, 1995. 